\title{
Strategies of Chinese translation of American teleplays based on Skopos Theory-A case study of American teleplay House of Cards
}

\author{
Shuyan Yu \\ School of Foreign Languages \\ Shanghai University of Engineering Science \\ Shanghai, China \\ Shengli Wang (Corresponding author) \\ School of Foreign Languages \\ Shanghai University of Engineering Science \\ Shanghai, China \\ E-mail: wangvictoire@hotmail.com \\ Yuying Xiao \\ School of Foreign Languages \\ Shanghai University of Engineering Science \\ Shanghai, China
}

Received: May 2, $2017 \quad$ Accepted: June 2, $2017 \quad$ Published: June 6, 2017
$\begin{aligned} & \text { doi:10.5296/ijld.v7i2.11155 } \quad \text { URL: https://doi.org/10.5296/ijld.v7i2.11155 }\end{aligned}$

Supported by Shanghai University Students Innovation Training Program (cs1621006)

\begin{abstract}
With a wide spread of American teleplays in China, teleplay translation has become an urgent task for giving viewers access to teleplay appreciation. Based on Skopos Theory, this thesis carried out a tentative study on teleplay translation according to a case study of American teleplay House of Cards. The Skopos of teleplay is to provide, within the constraints of time and space, the well-translated teleplays which aid viewers to understand the content of teleplay well. In order to translate purposefully and fulfill the Skopos of the teleplay translation, translators have to adopt certain principles respecting the target culture and particular strategies in the process of teleplay translation. This essay discussed the characters and functions of teleplays as well as the detailed information of Skopos Theory.
\end{abstract}

Keywords: Chinese translation; American teleplay; Skopos theory; House of Cards 


\section{Introduction}

In modern times, there are various ways of culture transmission within the change of times. As a comprehensive art form, teleplay, teledrama, or TV series is an integration of variety artistic means which is able to disseminate information, express feelings, reflect the colorfulness of life, thus to give a sensible enjoyment to viewers. Nowadays, as the Sino-foreign cultural exchange continues to be strengthened, a great number of foreign teleplays have been brought in as a way of cultural transmission. The translation of teleplay is not only a brief and clear way to introduce foreign culture but also an important mean to spread national culture. In the flood import of foreign teleplays, teleplay translation acts as a magnificent guide to the Chinese viewers. A successful teleplay translation can be both funny and meaningful.

There have been many translation methods posed by scholars. In terms of the difference between east-west cultures, literal translation may not satisfy Chinese viewers. Skopos Theory, put forward by Hans Vermeer, forms the main structure of the functionalist translation theory. It does not only focus on translation at the linguistic level, but also emphasizes the roles of the translator and culture in translation. "The end decides the means" is its most distinctive feature, which allows much room for the translator in the use of a satisfactory method to solve the problems occurred when they translate. The purpose of American teleplay translation decides that translation is a highly creative artistic activity. Therefore, following the basic guiding ideology and the general laws of translation, the authors explore the unique rules and methods of teleplay translation.

\section{A Brief introduction of Skopos Theory}

Skopos is the Greek word for "aim" or "purpose" and was introduced into translation theory in the 1970s by Hans J. Vermeer as a technical term for the purpose of a translation and of the action of translating. To break with traditional linguistic translation theory, Vermeer thinks that translation is an intercultural action. It is not "the transcoding of words or sentences from one language into another, but a complex action in which someone provides information about a text under new functional, cultural and linguistic conditions and in a new situation". Vermeer believes that Skopos Theory stresses the inter-actionable, pragmatic aspects of translation, arguing that the shape of teleplay translation should be determined by the function or "skopos". Reiss \& Vermeer demonstrate that "an interaction is determined by (or is a function of) its purpose" and "the skopos can be said to vary according to the recipient". On such a basis, the translator should use the translation strategies which are most appropriate to achieve the purpose for which teleplay translation is intended, irrespective of whether they are considered to be the "standard" way to proceed in a particular translation context; in a short word, when producing a teleplay translation "the end justifies the means". A translational action has all kinds of translation skopos, which are related to each other in a hierarchical order and determine the translation methods. An awareness of the requirements of the skopos "expands the possibilities of translation, increases the range of possible translation strategies, and releases the translator from the corset of an enforced - and hence often meaningless - literalness". 
2.1 Four stages of Skopos Theory

\subsubsection{Katharina Reiss's Functionalism}

First, Katharina Reiss put forward the embryonic form of functional school of thought. On the one hand she still adhered to the equivalent theory which focuses on the original work, on the other hand, in practice, Reiss found that sometimes the equivalence cannot be realized and should not be pursued. Both exceptions have allowed the functional perceptive in the translation process to overrule the equivalence standards. According to Reiss, the ideal translation would be one "in which the aim in the target language is equivalence as regards the conceptual content, linguistic form communicative function of a source language text" (Christiane Nord, 2004, 9). In this case, Reiss believed that the translator should give priority to the functional characteristics instead of the principle of equivalence.

\subsubsection{Han J. Vermeer's Skopos Theory}

Later, her student Hans Vermeer founded the Skopos Theory on her theory basis, further freeing the translation from the original language shackles and getting rid of the text center theory. According to the theory of behavior, he proposed that translation is an act of human activities and a purposeful behavior activity. The first rule translation should follow is the purpose of law and the purpose here refers to the communicative purpose of the text. Furthermore, since situations are integrated with cultures, any evaluation of a particular situation, of its verbalized and non-verbalized elements, depends on the status it has in a particular culture system.

\subsubsection{Justa Holz-Manttari's Theory about Translational Action}

On the third stage, Justa further developed the functionalist translation theory. She regarded the translation as "complex activities" to achieve a particular purpose. That is to say that translation is the act which the translator chooses from the multi-source provided by the original work as well as a cultural comparison. Translators explain "the other thing" based on their specific cultural knowledge. Actually translation has been seen as the behavior in the specific cultural context, not acting in vacuums proposed by the structuralism translator. Instead of speaking of the term "translation", she always uses "message transmitters", consisting of textual material combined with other media such as pictures, sounds and body movements.

\subsubsection{Christiane Nord's function plus loyalty model}

Christiane Nord, professor of translation, one of the leading advocates of the functional school in Germany, added the principles of loyalty into the rules of Skopos Theory: the responsibility translators have toward their original works in translational interaction. To some extent, that improvement decreases the criticism on the teleological function, and further refines this theory as well as expands its influence.

\subsection{Three rules of Skopos Theory}

According to Skopos Theory, the prime principle determining any translation process is the purpose (Skopos) of the overall translational action. The Skopos usually refers to the purpose of the target text. The top-ranking rule for any translation is thus the Skopos rule, that is, "the end justifies the means". This rule can solve the restrained disputes involving free vs. faithful translation, dynamic vs. formal equivalence, good interpreters vs. slavish translators and so 
on. It means that depending on the purpose for which the translation is needed, the Skopos of a particular translation task may require the translator to adopt a 'free' or a 'faithful' translation, or anything between these two extremes (Li Qun, 2002, 41).

Besides Skopos rule, the more specific aspect of Skopos Theory is the relationship between the source and target texts within a functionalist framework, that is, intertextual and intratextual coherence, which form into the coherence rule and fidelity rule. Coherence rule refers to that the target text should conform to the standard of intratextual coherence, which specifies that a translation should be acceptable in a sense that it is coherent with the receivers' situation. This means the receiver should be able to understand it; it should make sense in the communicative situation and culture in which it is received. For this reason, in the process of translation, the translator should take the target culture into careful consideration and do some alternations in order to make the translation intelligible. Otherwise, the translated text may lose its significance and become meaningless in the target culture.

Since translation is an offer of information from the source text, the translated text must bear certain relation with the source one. Vermeer calls this relationship "intertextual coherence" or "fidelity". This coherence exists between source and target text and the form it takes depends both on the translator's interpretation of the source text and on the translation Skopos. One possible kind of intertextual coherence could be a maximally faithful imitation of the source text.

\subsection{Contributions of Skopos Theory}

Vermeer (1989) claimed that a major contribution of Skopos Theory is to "increase the choice of translation strategies, make the translators more free so that they do not have to be limited by the meaningless literal translation imposed on them" (Zhang Nanfeng, 2004, 210). Thus under the particular context, adding, deletion, adjustment or rewriting provide a theoretical basis to some indigents of the source text. Compared with the traditional "Equivalent Theory", Skopos Theory focused on choosing the best way based on various contexts footed on its expected functions instead of whether it is equivalent with the source text. Therefore, it has a higher scientific operability.

\subsubsection{A New Definition of Translation}

According to Skopos Theory, translation is an intentional, interpersonal, and partly verbal intercultural interaction based on a source text, which focuses the involvement of multiple personal and cultural factors in translation process. Thus, the scope of translation studies was widened and branched out beyond the linguistic boundary, which broadens the horizon of translation studies and helps to explain the complexity of translation.

\subsubsection{Changes of the Status of ST and TT}

An important impact of Skopos Theory is that it completely changes the status of ST and TT. The source is dethroned and just becomes an offer of information, which is no longer the supreme yardstick for translation. With the falling of ST status, the target text rises to the focus. The translator can be released from the restrictions imposed by a narrowly defined concept of loyalty to the source text alone and have the initiative in translation.

\subsubsection{New Attitude toward Translation Strategies}

Skopos Theory can be paraphrased as the translation purpose justifies the translation 
procedure. If a translation fulfills the primary purpose of translation, it is believed to be a successful translation, whatever translation strategies the translator takes. So Skopos Theory takes a more tolerant attitude to translation practice, especially those that are usually considered to be against the existing translation criteria but proves to be satisfactory and successful in outcome.

\section{An Analysis of American Teleplays}

China is currently in a transitional period, leaving its door open to foreign pop cultures. With the development of personal computers and high-speed Internet, foreign cultural products such as imported TV dramas are flooding into the Chinese market through television and digital interfaces (Chamberlain, 2010). Exposure to foreign TV series has created a demanding audience in China (Fung \& Ma, 2002). Among these foreign TV series, the American TV series are the undisputed leader in the international marketplace (Bielby \& Harrington, 2005). As an influential cultural entertainment form, the American TV series not only brings a lot of fresh audio-visual experience to the Chinese audiences, but also conveys American culture and values, which usually expresses a televisual version of modernity more intense than the current Chinese socio-scape (Fung \& Ma, 2002). So watching TV series is a fun and entertaining way to immerse yourself in the language and cultural context, which offers you the benefits of visual comprehension, especially while learning a second language. Chinese audiences have been exposed to American TV series since the 1980s, during China's opening up phase, but it's really during the new century that their popularity has taken off here. In recent years, American teleplays or television series like House of Cards and 2 Broke Girls have become increasingly watched in China -- with more Chinese content providers gaining licenses to release them. Chinese viewers wanted to learn English from the very beginning. And now the authors think it's more about entertainment. Thanks to professional (and voluntary) Chinese subtitle teams who translate and embed subtitles into American television shows and then post them online 24 hours after every new episode comes out, Chinese audience are becoming more culturally sophisticated and interested in niche American shows.

A lot of popular American teleplays are available to the Chinese people, such as House of Cards, The Walking Dead, Agents of S.H.I.E.L.D., Vampire Diaries, 2 Broke Girls, Breaking Bad, Gossip Girl, The Flash, NCIS, Friends, and Game of Thrones. The authors selected the script translation of the teleplay House of Cards and analysed the translation methods or strategies.

House of Cards is popular because of the popularity of scandal stories in Chinese culture, and because Chinese people find the spectacle of American democracy refreshingly new and entertaining. The show appeals to Chinese who are interested in world affairs, particularly America. The Chinese government is frequently mentioned and plays an important role in the plot of the show, which has also made the show popular with the government. The show is quoted by Chinese officials, and in general, the ambitious Frank Underwood is an admirable character in the Chinese eyes. The show enjoys the most popularity in Beijing, which speaks to how it appeals to a politically savvy crowd. It is not a coincidence that the show has become popular during a time of government action against corruption, and some fans take pleasure in seeing that the American system and theirs have some things in common. The 
show probably appeals most to Chinese people who feel it tells them more about American politics than the real news, as they are familiar with corruption scandals in their own country.

There's no doubt that a good translation of American teleplays could add charm to the teleplays and influence the audience ratings. The American teleplays have their own linguistic, aesthetic and cultural features and functions, to which the translator should pay much attention. It is quite necessary to make a general analysis of the American teleplays in order that it will provide a better understanding of the research subject before the authors come to the core.

Although teleplays have something in common with other literary forms, they are a video art as well as an important part of cultural exchanges between countries. A successful teleplay translation can arouse the viewers' attention and favor. In a word, the translation of teleplays is not a simple mechanical movement copying the content and form of the original(Zhang Chunbai, 1998, 02). Translation should take into account all of the value function and strive to make the translation receive the desired effect, maximizing the intended purpose and function of the teleplay translation.

\section{Application of Skopos Theory to Teleplay Translation}

\subsection{A Functional Analysis of Teleplay Translation}

\subsubsection{Teleplay Translation as Purposeful Activity}

Generally, it is obvious that the purpose of teleplay translation is to help the viewers have a good understanding of the content of the teleplay, and provide expressive and aesthetic feeling to the viewers. For translators, translating teleplays can be seen his own work which may be his living tool. So a successful translation can win him great fame as well as fortune. This is the general purpose of any translation. Translators often use as many strategies as they can to make the targets more accurate and more enjoyable. This is just the core of Skopos Theory, namely, "the end justifies the means" (Christiane Nord, 2004, 21). The purpose of using particular translation strategies is to instruct and entertain the viewers.

Therefore, a successful teleplay should arouse the viewers' interest, leaving the world an amazing surprise just like House of Cards, The Walking Dead, and Game of Thrones. Besides the stars in the teleplay, the viewers' great interest and desire could be kindled by a good translation of teleplay. That is to say, the ultimate goal of teleplay translation is to arouse the viewers' interest and trigger them to watch more and more often.

\subsubsection{Teleplay Translation as an Interpersonal Interaction}

Translating itself is also an interpersonal interaction, in which many agents are involved. First, the producer, who is responsible for initiating a teleplay, providing money and original thoughts to the teleplay, occupies a dominate position in the whole process. Second, the director, who can be compared the boss of the whole cast, playing the role of commissioner and target-text user in one person, sets the tone and lays the style of the teleplay. He is interpreting the theme of the teleplay and delivering the message that the teleplay wants to give us, which composes a translation brief. Third, the screenwriter, for example, the original script maker, acts as the source-text producer, who will not be involved in the action of translating teleplays. In many cases, directors cooperate with the screenwriters accomplishing the story-making, the frame work and other specific tasks of the teleplay. Forth, the viewers, 
who are the target-text receiver, will have a direct feeling about the teleplay. Their reflections are like barometer that will have an influence on the feedback and results of making one teleplay. Fifth, the translator, who is the target-text producer in this case, will shoulder the translation job. His job successfully decides how many Chinese people will enjoy watching it.

The intended target-text receivers are the addressees of the translation, which is thus a decisive factor in the production of the target text. The viewers are from all walks of life, different in age, vocation and educational level so they have different tastes. Basically, the intended viewers are ordinary people, who watch a teleplay mainly for entertainment or broadening their visions. For those reasons, the teleplay translator should take the expectations into consideration, the communicative needs and the culture-specific world-knowledge of the viewers in order to translate a teleplay which is attractive enough and could trigger viewers to watch the drama. Target-text producer should get a good understanding about the needs and tastes of common people in order to translate the teleplay into a level that can be accepted by most ordinary people. In practice, the process of such translational action may be much more complicated than what has been stated in the preceding paragraphs. Only through the good cooperation of all sides can a wonderful excellent translated work be produced.

\subsubsection{Teleplay Translation as an Intercultural Action}

In Skopos Theory, the concept of culture is also important. According to Vermeer, every cultural phenomenon is assigned a position in a complex system of values. And every individual is an element in a system of space-time coordination. Thus trans-cultural action or communication across culture barriers has to take account of cultural differences with regard to behavior, evaluation, customs and communicative situations. With the cultural exchange between nations becoming more and more prosperous, hundreds of English audiovisual products enter the Chinese market each year. Being the social product of cultural phenomena and ideological trend, teleplays abound in cultural elements, which can enable the ordinary Chinese people to experience the exoticism such as different life patterns, unique social customs, value systems, etc. Teleplays are inevitably branded by the typical nation characteristics and cultural value. It is a common practice for the screenwriters to present teleplays with cultural-loaded words, typically idioms, slang and allusions. Therefore, teleplay translation is a cross-cultural activity in nature. For example,

Frank: Linda Vasquez, Walker's chief of staff. I got her hired. She's a woman, check. And a Latina, check. But more important than that, she's as tough as two-dollar steak. Check, check, check. (Episode 1, Season 1) 是我找来了她, 她是个女人。又是拉丁裔。但更重要的是她像一块 廉价牛排一样坚韧。样样都符合标准。

This is part of the monologue said by Frank. When it comes to Linda Vasquez, Frank stated his reasons why he chose her as the chief of staff one by one. There are two "check"s after the first two reasons and end with a "check, check, check". If the translator chooses the domestication way, "check" here means “打钩”. For the original audiences, this is such a pictorial expression that they could see the action of ticking in a list. To make Chinese audiences easy to understand, the previous two "check"s are neglected in the whole subtitle and the last words are translated as “样样都符合标准”, by which the reasons Frank states 
could be clarified.

The above example shows that translating should be done after comparing cultures and in accordance with the context of a specific culture. Translators interpret source-culture phenomena in the light of their own culture-specific knowledge. Therefore, in the Skopos Theory, translation is looked on as "offering information to members of one culture in their language (the target language and culture) about information originally offered in another language within another culture (the source language and culture)" (Baker Mona \& Kirsten Malmkjear Routledge, 1998, 236).

\subsection{Translation Strategies Adopted in Teleplay Translation}

\subsubsection{Transliteration}

Transliteration means to pursue phonetic correspondence, and the similar sound of the people or place in the teleplay may give the viewers a hint to guide them to enjoy it more in the teleplay. Transliteration is employed in the translation of teleplays, for it helps to keep the rhythm and form of the original drama and attract the viewers' attention by its typical foreign flavor. In other words, by means of transliteration, the translated versions in the target language can obtain the characteristic of the teleplays and achieve the expressive function and fulfill the vocative function by giving the viewers a sense of exotic flavor. This strategy is indispensable in nowadays translation. Thus, common names, proper names, and terminological names can be translated directly. For example, Claire (克莱尔), Doug (道格); Prime Minister (首相), Democrat (民族党人), Republican (共和党人); the metallic element “uranium" (铀); the company name Sancorp (桑科). Some words like Vasquez (瓦斯奎兹) and Oklahoma (俄克拉何马州) that are harder to pronounce and recognize may affect the whole watching. In such cases, it is suggested call them short for quicker reading without harming the translation quality. For example, translating “Philadelphia” as “宾州” is better than “宾夕 法尼亚州”.

Almost all words have denotations and connotations. Transliteration method may make the original words lose their connotations which are ideas that are suggested by or associated with the words. The typical example is the hero of the teleplay, Francis Joseph "Frank" Underwood (弗兰西斯・约瑟夫•弗兰克・安德伍德). The word underwood means the brush (small trees and bushes and ferns etc.) growing beneath taller trees in a wood or forest, while the close-up of Underwood's cuff of a sleeve is capital letters FU (initials of Frank Underwood) which implies the word FUCK or "FUCK YOU". The full name is the demonstration of his personality. Frank is a patient, cold, duplicitous, cunning, and ruthless politician who knows exactly how to take what he wants. Displayed as a power-hungry man with the skills and the resources to match, his quest for power and vengeance leads him to break old alliances and trample on and destroy those that stand in his way. He has no qualms of killing people or ruining their lives and careers if it serves his goals.

\subsubsection{Literal Translation}

Literal translation means translating literally, keeping both the original form and the original content. Functionalism does not exclude equivalence so long as it is adequate to a Skopos that requires that the target text serve the same communicative function or functions as the source text. If the translator can find in the target language an expression that is completely or 
almost equivalent to the one in the source language, literal translation is advisable.

A teleplay could be translated word for word or with some adjustment of word order or structure, if its corresponding expression in the target language can achieve the same informative, expressive and appellative functions of the original. Under this circumstance, the viewers can find a perfect match and are interested in the foreign elements.

Example 1

The majority whip's wife stabs him in the back.

多数党党鞭的妻子在背后捅他刀子.

There are almost the same expressions that could convey the same meanings in English and Chinese, and the translator could just translate the words easily, which are acceptable both in China and America.

\section{Example 2}

Jim Matthews, his right honorably Vice-President, Former Governor of Pennsylvania. He did his duty in delivering the Keystone State... Linda Vasquez, Walker's chief of staff. I got her hired. She's a woman... As for me, I'm just a lowly house majority whip... (Episode 1, Season 1)

吉姆·马修斯, 尊敬的副总统阁下, 前宾夕法尼亚州州长, 他帮总统拿下了宾州。......琳达·瓦斯奎兹, 沃克的幕僚长。是我找来了她, 她是个女人......而我, 我只是卑微的众议院多数党党鞭......

This passage was a section of monologue uttered by the protagonist Frank Underwood at the beginning of the first episode, in which he briefly introduced several other characters and their positions who present on the screen. In this passage, there are several terms that are specific. Words like "president" and "governor" are needless to discuss which are rather familiar to Chinese audiences nowadays. Other terms like "chief of staff" and "house majority whip" are the positions in the American government that Chinese people may not know. A chief of staff is the leader of a complex organization, institution, or body of persons who is the coordinator of the supporting staff or a primary adjutant to an important individual, such as a president or a senior military officer. A whip is an official in a political party whose primary purpose is to ensure party discipline in a legislature. They are literally translated into “幕僚长” and “众议院多数党党鞭”. There are other examples using literal translation can be found in this example, such as the names of people "Jim Matthews" and "Linda Vasquez".

Nevertheless, literal translation also poses problems in teleplay translation, such as ambiguity in meaning, incompatibility between the forms of the version and the original content, cultural element which is unacceptable to the Chinese language, and so on. So the translators need other teleplay translation methods so that the viewers can be better informed.

\subsubsection{Free Translation}

Free or liberal translation is a strategy which seeks to convey the meaning and the spirit of the original subtitle without sticking to the form mechanically. There are no two identical languages in this world, so it is impossible for translators to find exact equivalent words or phrases in the target language all the time. To make the Chinese version fulfill the Skopos of teleplay translation, the translator often resorts to liberal translation when and where necessary. As teleplay translation focuses on the target viewers and serves the purpose of 


\section{Macrothink

better communication, it is easier for translators to understand the frequent employment of free strategies in teleplay translation, and it is an effort to reproduce the function of the original teleplays to achieve the ultimate purpose of teleplay translation.

The most important point of this technique is that such combination can transmit the message to the most extent and add to the artistic appeal of the subtitle since literal translation can deliver the literal meaning of the subtitle at the surface level, and at the same time liberal translation expresses the implied meaning of the subtitle in depth. There are also many ways when using liberal translation strategy like addition, extension and shift of speech.

\section{Example 3}

Lucas: Your nights and weekends are yours, I applaud whatever you want to do as long as its not on my time. (Episode 1, Season 1)

卢卡斯：你自己的时间随意支配，你想做什么我都没意见，但不能占用工作时间。

This utterance was what Lucas said to Zoe. Zoe was an ambitious young political reporter who felt unappreciated and depressed at first. She wanted to do something big like writing online reports or blogs instead of attending boring meetings. Lucas is Zoe's superior who was kind of old-fashioned and he wouldn't let the paper he's editing become a gossip column. This translation sounds exactly like a boss, which is familiar and natural to Chinese audiences. In most cases the meaning may not be conveyed correctly if the translators translate the sentence word by word due to the differences between Chinese and English. Even if they could mean similarly, the literary translated version are still hard to pronounce which may cause confusion for the audiences. There are some other typical examples using free translation strategy listed as below.

\section{Example 4}

I end your race so you end mine? (Episode 3, Season 4)

我终结了你的竞选，所以你以牙还牙?

\section{Example 5}

This could be seen as an election stunt. He's trailing Dunbar in the polls, so he wants to save the day. (Episode 10, Season 3)

这可被视为选举作秀。他在民调中落后邓, 所以想挽救大局。

Example 6

She believes in Claire, which inclines her to believe in you. I meant every syllable. (Episode 13, Season 2)

她信任克莱尔，所以她也想相信你，我字字发自肺腑。

Example 7

And it's on the FBI. And it is a shit-storm that will bring the Bureau right in front of Congress. (Episode 12, Season 2)

联调局也罪责难逃，这会闹得很难看，让联调局面临国会的调查。

\section{Example 8}

Frank: You were gonna play pit bull while I play presidential. Will you get a little bloody? Yes, probably. But that's what people want in their debates. And then you and I together, we 
bury her. (Episode 11, Season 3)

你咄咄逼人, 我保持气度, 你会惹火上身吗? 对, 有可能, 但这不就是辩论的目的吗, 然后你与我 携手, 我们一起埋了她。

Example 9

I don't plan on making any fuss in the press. You'll hear nothing but my praises if I'm asked. (Episode 8, Season 2)

我不想造成任何與论风波, 如果有人问, 我一定都是溢美之辞。

Actually, in any types of translation, both literal and free translation are used frequently. In most cases, these two practical strategies are combined to make the translation more natural and closer to the original texts. A good translation should not focus on one single strategy simply, but make a specific analysis on the concrete problems.

\section{Conclusion}

With a wide spread of American teleplays in China, teleplay translation has become an urgent task for giving viewers access to teleplay appreciation. However, actually teleplay translation is still largely unexplored in the field of translation studies. There is an obvious inconsistency between the apparent importance and prevalence of teleplay translation. Based on Skopos Theory, this thesis carried out a tentative study on teleplay translation. In terms of Skopos Theory, teleplay translation is a purposeful action. The Skopos of teleplay is to provide, within the constraints of time and space, the well-translated teleplays which aid viewers to understand the content of teleplay well. In order to translate purposefully and fulfill the Skopos of the teleplay translation, translators have to adopt certain principles respecting the target culture and particular strategies in the process of teleplay translation. This essay discussed the characters and functions of teleplays as well as the detailed information of Skopos Theory. And most importantly, application of Skopos Theory was emphasized.

The Skopos translation is no longer a plain-language conversion process, but rather the conversion of culture, aesthetics and values between the source language and target language. The teleplay translation is determined by the intended purpose or function of the teleplay translation, it is necessary to follow the principles and methods of the translation, but also needs to have a wealth of cultural knowledge and a solid language foundation. Teleplay translation, according to the content and ideas of the teleplay, should consider the similarities and differences of Eastern and Western cultures as well as the acceptability of the translation. In this way, translation passes teleplay information and culture, aesthetic beauty, thus helping to improve viewers' English proficiency.

However, because the authors have limited knowledge about teleplays and lack practical related experience, the discussion of this thesis is limited in the depth and width of research. There are some limitations which need further improvement.

\section{References}

Author name (Year, Month day). Retrieved from http://translation21st.blog.sohu.com/13861664.html

Baker, M., \& Kirsten, M. R. (1998). Encyclopedia of Translation Studies. London and ew York: 236. 


\section{Macrothink}

International Journal of Learning and Development

ISSN 2164-4063 2017, Vol. 7, No. 2

Chen, X. (2000). The Enlightenment of Translation Functional Theory--Some New Thoughts on Some Translation Methods. Chinese Translators Journal. 2(4), 31-33.

Christiane, N. (2004). Translating as a Purposeful Activity: Functionalist Approaches Explained. Shanghai Foreign Language Education Press.

Delabastita, D. (1989). Translation and Mass-communication: Film and TV Translation as Evidence of Cultural Dynamics. Babel. https://doi.org/10.1075/babel.35.4.02del

Eugene Nida. Retrieved May 19, 2017, from http://en.wikipedia.org/wiki/Eugene_Nida

Gambier, Y. (2003). Screen Translation: Perception and Reception. Jerome Publishing.

Hatim, B., \& Mason, I. (1997). The Translator as Communicator. London: Rouledge.

House of Cards (U.S. TV series). Retrieved May 19, 2017, from https://en.wikipedia.org/wiki/House_of_Cards_(U.S._TV_series)

Jeremy, M. (2001). Introducing Translation Studies-Theory and Applications. London \& New York, Routledge.

Li, H., \& Bo, Z. (2005). Specification and Subtitle Translation. Chinese Science \& Technology Translators Journal, 2, 44-46.

Li, Y. (2001). The Strategy of Subtitle Translation. Chinese Translators Journal. 4, 38-40.

Lou, B. (1994). On the Translation of Film and TV Plays. Journal of Shanghai Jiaotong University (Philosophy and Social Sciences). 2, 102-104.

Luyken, M. (1991). Overcoming Language Barriers in Television: Dubbing and Subtitling for the European Audience. London: University of Luton Press.

Qian, S. (2000). Film and Television Translation--One More and More Important Translation Area. Chinese Translators Journal. 1, 61-65.

Zhang, C. (1998). On the Translation of Film and Television. Chinese Translators Journal. 2, 49-52.

Zhang, N. (2004). Criticism of Chinese and Western Translation Studies. Beijing: Tsinghua University Press. 210.

\section{Copyright Disclaimer}

Copyright for this article is retained by the author(s), with first publication rights granted to the journal.

This is an open-access article distributed under the terms and conditions of the Creative Commons Attribution license (http://creativecommons.org/licenses/by/4.0/). 